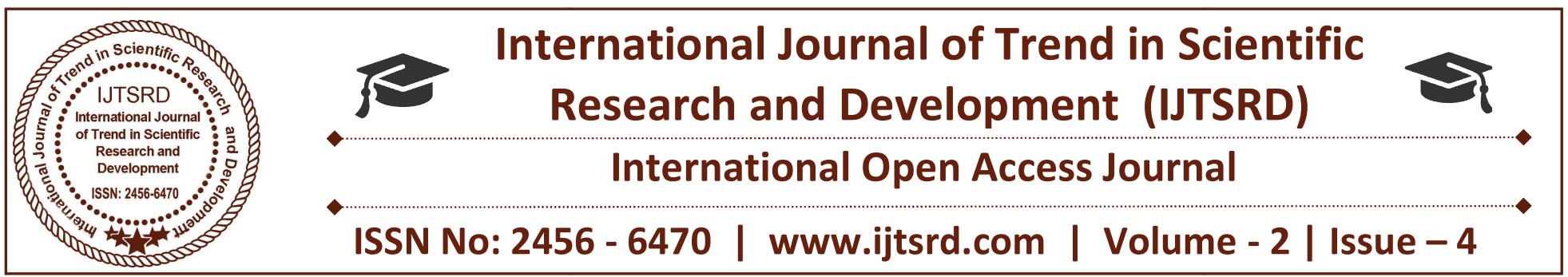

\title{
Techniques to Analyse, Identify \& Verify the Online Job Offers by Fake Companies World Wide
}

\author{
Athira Das, Swati Ashok Desale \\ MCA Department, Mumbai University \\ ASM's Institute of Management and Computer Studies \\ Thane, Maharashtra, India
}

\begin{abstract}
The growing internet technologies have made it easier for the job seekers to search and apply for the jobs by just few clicks on mouse using internet. This makes the person to do fewer efforts on searching for jobs offline and gets trapped by the fraudster. A job scam is nothing but a group of fraudulent activity which the team acts as a real recruiter and post good job offers with a huge amount of pay scale. The primary goal of them is to loot huge amount from the job seekers by two methods. One method is the fake recruiter asks to wire some huge amount of money as an advance before confirming the job and the second method is identity theft. In the identity theft method, the fake recruiter from the fake companies approaches people and tries to get the persons confidential information in the name of job opportunity and then uses the personal information's for theft identity. No matter what method they use to approach job seeker, their primary and main intention is to fetch a huge amount of money and escape. In this growing technical world, the fake recruiters of fake companies have many smart tricks in hand which makes it extremely difficult to identify and verify the real companies from the fake one through online. As the online job openings are increasing, the fake recruiters and companies online are also increasing enormously day by day. In the internet if we identify and verify the job openings, there will be approximately only 4 out of 10 legitimate openings and rest of the openings are identified as fake companies and recruiters.
\end{abstract}

Keywords: Fake Companies; Recruiter; Scammers; Candidates

\section{INTRODUCTION}

Many companies provide job openings online. But the job seekers should also know the worst effects of searching jobs online.

One common type of fake recruiting scam is targeting people who seeks job overseas. The recruiter from fake company approach the candidates who search for job with an attractive job opening in overseas with a good amount of package and they make a promise to take care of travel visa, work permit and other allowances.

Once the fraudster receives the amount they totally move apart with no online fake site, no identical traces over the internet nor with the organization physically. The techniques to verify the companies are Research the Company, Use Google to cross verify, Check Scam List, Check email accounts, Cross verify URL's, Suspect demand of wiring money before getting hired and Verify with Registrar of Companies(ROC).

\section{Problem Definition}

The most known faking is done with the people who seek jobs overseas.

The fake recruiting companies offers an attractive openings and high pay scale with lot many benefits like take care of work permit \& travel visa, free accommodation, travelling and food allowance etc. in overseas. 
People gets easily attracted towards such promises and they themselves or the recruiting companies approaches them.

And then they ask the candidate to perform some procedures that will economically or in any other way benefits the fake company.

Once they receive the benefits they were targeting, they move apart totally with no identical traces in the internet nor with name of the company.

When taken the literature survey of Online Fake Job Recruiting Companies across the world, United States stands first in this. Out of 400 Recruiters it is found that 359 of them are fake.

III. Techniques to Analyse, Identify \& Verify Fake Companies who provides Job Offers Online

The techniques used to verify fake online job offers by fake companies are as follows:
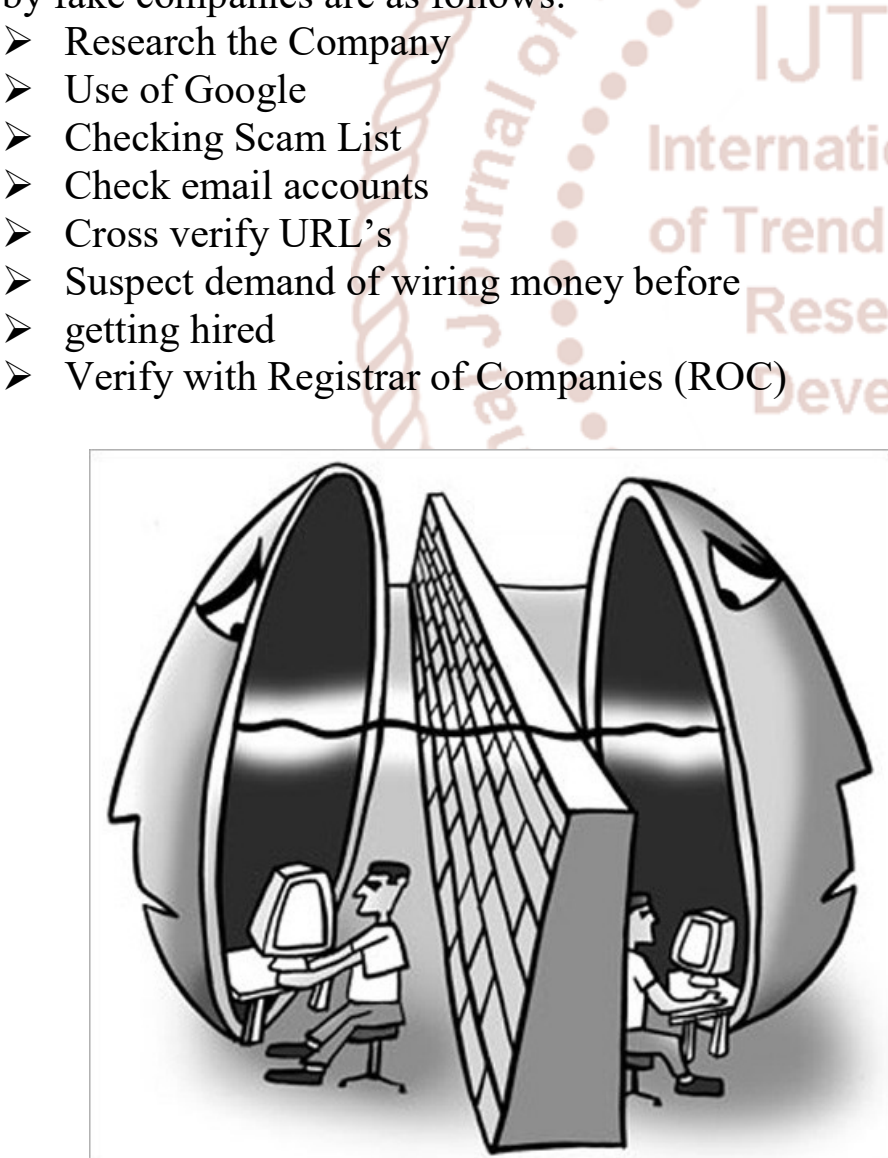

Fig. 1 Image of Fraudsters

\section{A. Research the Company}

Due to the increase in fake online job offers it is very necessary to check the company before you approach them to seek a job.
Therefore, researching the company will be very first step the candidate must perform.

There are some serious key signs that must be noticed during the job applying procedure.

If there is no official website for the company who offered the job, then it is suspicious and rethinks before you proceed with the offer.

\section{B. Use of Google}

Google helps in Studying about the company online and the job offered by them. Through Google we can get the various details about them.

After receiving the basic details of the company, a deep research on the internet is beneficiary to know about the company.

Cross check the details provided to you by the recruiter of that company with the details in the internet. There are high chances of using fake organizations name by the fake companies to make money from the candidates on the name of attractive job offers.Also, there are many cases where the fake company use reputed companies name and make some minor changes to the name of the company to create a misunderstanding to trap the candidates and make money from them.

The unique way of finding fake companies is checking their address with the help of Google map, mostly the fake company's uses the fake address. Therefore, Google map can help in finding this.

\section{Checking Scam List}

Checking scam list is the very effective way to verify the company to which the job has been offered. This can be done by referring the well-known organizations like 'Federal Trade Commission' and 'Better Business Bureau'.

\section{Check E-mail Address}

In this generation, every organizations and other companies have a corporate email address. In case any company approaches you with open email address like yahoo, Gmail, Hotmail or live then there is a major chance to be a fake company. Trusted job openings from a recognized company will mostly have corporate email id's. Do not trust or proceed with free email accounts. And always notice these kinds of small things the fraudsters do. 
From: newrecruit.tcs@hotmail.com

Subject: Interview Notification

Dear applicant,

Congratulations! You have been selected by TCS as a

Software Tester.

You are expected to deposit a cash of 12, 200/-(Twelve

thousand two hundred rupees) as an initial amount in favour of our Company' account offer's name in charge of payment.

\section{Senior H.R Manager}

TATA CINSIIITANCY SFRVICF

Fig. 2 Image Example of a message from fake company to the candidate through Email

\section{E. Cross Verify URLs}

One of the best and simple way to find the fake online companies are finding the fake URL's.

Always do a cross verification of the URL to get it known that whether it is true or fake.

Most of the fake company websites uses fake URL's to show themselves as a big and know corporate.

\section{F. Suspect the Demand of Wiring Money Before Getting Hired}

Do not pay money if online job agency asks to pay money immediately.

No reputed company demands for money before the candidate is hired.

If in case, they demand to pay then for sure the company is fake.

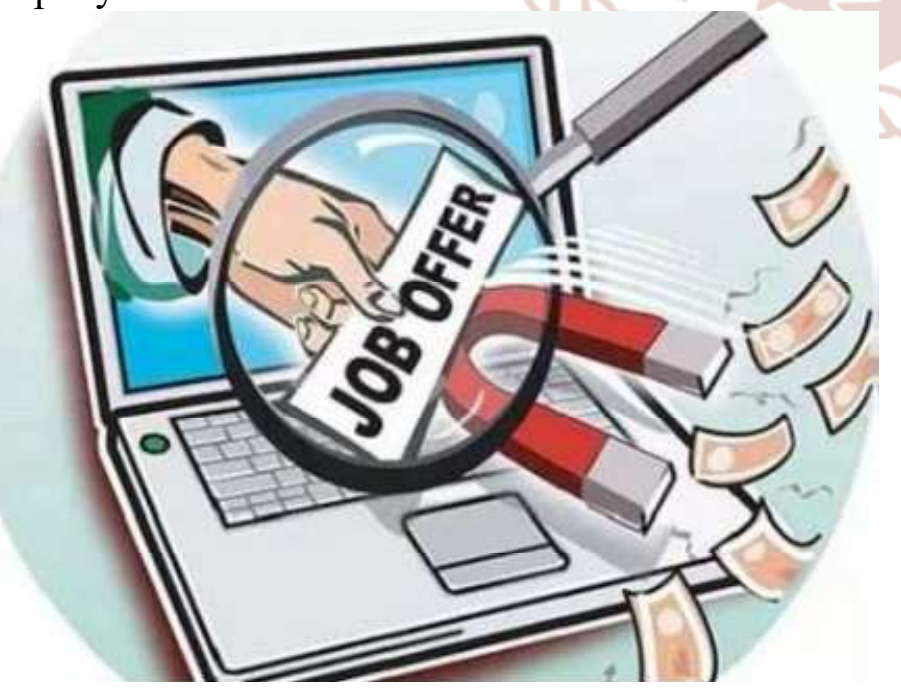

Fig. 3 Wiring money before getting hired

\section{G. Verify with Registrar of Companies}

The Registrar of Companies (ROC) is an office under the Ministry of Corporate Affairs (MCA), which maintains the records of existing companies and deals with the administration of companies and Limited Liability Partnerships in India.

At present, there is 22 operating Registrar of Companies (ROCs) in all major states.

States like Maharashtra and Tamil Nadu, have more than one ROC. The Registrar of Companies (ROC) maintains all the data's concerning companies in a registry of records which are registered with the ROC. And Registrar of Companies allows the general public to access the information regarding the company only on payment of a stipulates fee. The Central Government preserves administrative control over the Registrar of Companies with the help of Regional Directors. No trusted company can come into existence without the registration done with the Registrar of Companies (ROC). So, it is must that every company requires the registration and approval of the Registrar of Companies (ROC). After the registration and approval is done for a company, the ROC provides incorporation certificate which is the important evidence of the existence of any company. So, the candidate can verify the company through Registrar of Companies (ROC) office.

If the company from where the candidate has received job offer not a registered company, then the company is confirmed to be a fake company.

\section{Objectives}

The main objective of this research is to give a proper guidance before getting trapped by fake companies online to every job seekers throughout the world and reduce the number of victims who fall in such traps.

\section{Conclusion}

The consequences of getting trapped by scammers and fraudsters can include personal identity theft, loss of your money and illegal credit card charges.

This can be a very hard lesson for the job seekers who gets in their trap and devastating for economically low job seekers.

So before falling to such trap, you must check and verify every possible information's about the 
company through home and through different ways very carefully.

\section{Acknowledgment}

This research was supported/partially supported by Institute of Management and Computer Studies (IMCOST), Thane, India. We thank our Guide from IMCOST, Thane who provided guidance, insight and expertise that greatly assisted throughout the research, although they may not agree with all the conclusions or interpretations of this paper.

We thank Research Guide, Professor, IMCOST, Thane for comments that greatly improved the manuscript.

We would also like to show our gratitude to the institution for sharing their pearls of wisdom with us during this research.

\section{References}

1. https://content.wisestep.com/know-recruiterfakelying-tips/

2. https://www.consumer.ftc.gov/articles/0243- jobscams

3. https://campuscommune.tcs.com/enin/intro/view announcement/dont-be-mislead-byfake-offersvalidate-your-tcs-o-0

4. http://www.rediff.com/getahead/report/careerhowthe-tatas-are-fighting-jobscams/20150330.html

5. (2002) The IEEE website. [Online]. Available: http://www.ieee.org/

6. https://www.peoplematters.in/site/interstitial

7. https://cleartax.in/s/roc-registrar-ofcompaniesindia 